\title{
Prevalence and factors associated with cancellation of elective procedures on surgical wards at Mulago hospital, Uganda
}

alfred ogwal ( $\square$ oalfred4@gmail.com )

maracha hospital https://orcid.org/0000-0003-0057-6440

felix oyania

mbarara regional referral hospital

emmanuel nkonge

Kitovu Hospital

timothy kabanda makumbi

Makerere University College of Health Sciences

fred moses galukande

Makerere University College of Health Sciences

Research article

Keywords: cancellation, elective procedures, factors, prevalence

Posted Date: October 7th, 2019

DOI: https://doi.org/10.21203/rs.2.15648/v1

License: (9) This work is licensed under a Creative Commons Attribution 4.0 International License.

Read Full License 


\section{Prevalence and factors associated with} cancellation of elective procedures on surgical 3 wards at Mulago hospital, Uganda

Alfred Ogwal ${ }^{1 *}$, Felix Oyania ${ }^{[a], 1}$, Emmanuel Nkonge ${ }^{[b], 1}$, Timothy Kabanda Makumbi[c],1,2 and Fred Moses Galukande ${ }^{[\mathrm{d}]}, 1$

"Correspondence:

oalfred4@gmail.com,

a_smokie_|@yahoo.co.uk

${ }^{1}$ Surgery, Makerere University,

College of Health Sciences,

Kampala, Uganda

Full list of author information is

available at the end of the article

\section{Abstract}

Background: Cancellation of elective surgical procedures has been noted to waste resources and with potential to increase morbidity and mortality among patients. This study set out to determine the prevalence and factors associated with cancellation of elective surgical procedures at Mulago Hospital.

Methods: A prospective cross-sectional study was conducted from $10^{\text {th }}$ January 2018 to $20^{\text {th }}$ February 2018 . We recruited patients of all ages admitted on surgical wards and scheduled for elective surgery. Demographic data, diagnosis, specialty of surgery, proposed surgery, theatre and reasons for cancellation were extracted and analyzed using logistic regression.

Results: There were 115 procedures canceled out of 400 cases, giving us a prevalence of cancellation of $28.8 \%$. Neurosurgery had the highest cancellation rate at $46.8 \%(n=29), \mathrm{OR}=2.23,95 \% \mathrm{Cl}(1.22,4.06)$. UCl theatre was about two times more likely to have a procedure canceled $(\mathrm{OR}=2.12,95 \% \mathrm{Cl}$, $0.91-4.96)$. Facility factors contributed $67.8 \%$ to overall cancellations.

Commonestreason for case cancellations was theatre time run out. There was no procedure canceled due to lack of ICU bed. There was a significant association between specialty and surgical cancellation rate $(p<0.05)$.

Conclusions: The prevalence of cancellation of elective surgical procedures in Mulago Hospital is $28.8 \%$ with Neurosurgery having the highest cancellation rate. Two thirds of the factors responsible for procedure cancellations were facility related with more than fifty percent of them being potentially preventable. Quality improvement strategies are necessary in those sub specialties susceptible to procedure cancellations due to facility factors.

Keywords: cancellation; elective procedures; factors; prevalence 


\section{Background}

An elective surgical procedure is said to be canceled when a patient' s name has appeared on the list for surgical operations, but the operation is not done on the scheduled date [1]. Cancellation of elective surgeries has been found to range between $1.96 \%$ and $49 \%$ [2] [3]. In Western countries, about $20 \%$ of elective surgeries are canceled on the day of surgery [4]. However, in low income countries rates are as high as $48.5 \%$ [3]. Cancellation of a case is associated with wide-ranging clinical, psychological and economic consequences to the patients, hospitals and health care providers though the patients are the most affected [5]. Delayed surgical intervention may lead to deterioration of the patient' s condition and subsequently impaired recovery or even unexpected death [6] [7]. In addition, canceling a procedure can be very distressing to the patient, relatives and health care professionals [8]. It also results in unnecessarily prolonged hospital stay with resultant loss in working days, disruption of daily life and a heavy burden of healthcare costs [9]

The causes of cancellation of elective surgical procedures are multi-factorial, they tend to vary amongst health facilities and countries [10]. Key to note, most of the elective procedures are canceled due to various modifiable reasons [11] [12]. Previous studies have grouped reasons for cancellation into relatively broad categories while others simply list causes without grouping them [13].

In Uganda, cancellation of elective surgical operations is very common in routine clinical practice. However, no study has explored the reasons why these procedures are not performed on the scheduled dates. Moreover, the true prevalence of cancellation is not known. From previous studies done in low income and developed countries, there is a strong body of evidence suggesting that the burden is too high in developing countries. Therefore, this s study intended to establish the prevalence and factors associated with cancellation of elective surgical procedures among patients on surgical wards at Mulago Hospital, Uganda.

\section{Methods}

Study setting

[a] fellyx9@gmail.com

[b]nkongeemma@gmail.com

[c] tmakumbi@gmail.com

[d] mosesg@img.co.uk

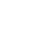

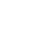

6

6

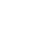

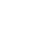

0


This study was conducted at Mulago National Referral and Teaching Hospital (MNRTH). MNRTH is a tertiary and teaching hospital for Makerere University ${ }^{2}$ College of Health Sciences (Mak CHS) and has a bed capacity of 1,790. However, 3 the hospital is currently undergoing a major renovation in the New Mulago Complex 4 with Department of Surgery, Department of Orthopaedics Surgery and Department ${ }^{5}$ of Pediatrics and Child Health shifted to Old Mulago. This study involved the 6 different surgical units that fall under the Directorate of Surgery and currently ${ }^{7}$ based in Old Mulago and these include General Surgery, Breast and Endocrine, ${ }^{8}$ Ear, Nose and Throat (ENT) Surgery, Paediatric Surgery, Neurosurgery, Cardiothoracic Surgery (CTS), Urological Surgery, Orthopaedic Surgery, and Oromax- 10 illofacial (OMF) Surgery. Elective surgeries in Old Mulago Hospital are currently ${ }^{11}$ performed in 7 different theatres and a 11 these theatres were functional during the ${ }^{12}$ entire study period.

At Mulago Hospital, elective surgical lists are made by the intern doctors and sur- ${ }^{14}$ gical residents in consultation with the surgeons attached to the different surgical specialties. Prior to admission on the wards all patients first attend surgical outpatients from where they are booked and given dates to come and check if there is bed space on the inpatients ward. It' $s$ on the respective inpatient wards that patients are supposed to be fully prepared and finally scheduled for elective procedure and the list signed by the surgeon responsible. The signed list is then taken to theatre the day prior to the actual procedure day by 14:00h. Elective operating lists begin at 08:00h and are required to be finished by 17:00h. Procedures are canceled at about 16:30h (at times earlier) if the corresponding procedure has no reasonable prospect of being completed by 17:00h.

\section{Study design and procedure}

This was a prospective cross-sectional study conducted from $10^{\text {th }}$ January 2018 to $20^{\text {th }}$ February 2018. A canceled procedure was said to occur when a patient' s name has appeared on the list for surgical operations but the operation is not done on the scheduled date. The patients included on the theatre list for the following day were consented, recruited into this study by the PI and research assistants. Collected data included demographic data, diagnosis, surgical specialty, proposed surgery, theatre and reasons for cancellation. The theatre nurse on duty was consented and interviewed by the study team to complete the questionnaire. Any individual 
who was part of the theatre and surgical team for the day was interviewed if any 1 clarification was warranted. 2

\section{Statistical analysis}

Completed questionnaires were double entered into Epidata version 3.1 with pro-

grammed quality control checks. After editing, data was exported to Stata 13.0

for analysis. For descriptive statistics, categorical variables were summarized using percentages and proportions while means, standard deviation, median and interquartile range were used for continuous variables. The overall prevalence of cancellation was calculated from the total number of cancellations divided by the total number of scheduled cases. Binary logistic model was used to identify any factors that were statistically associated with cancellation of elective procedures. The Odds Ratio and 95\% CI were estimated for the likelihood of cancellations for specialties and theatre. The level of significance was set at $\mathrm{P}<0.05$

\section{Ethical considerations}

This study was conducted with the approval of School of Medicine Research and Ethics Committee (SOMREC) of Makerere University College of Health Sciences, registered as \#REC REF 2018-007. Patients and /or next of kin consented to participate in this study.

\section{Results}

400 participants were recruited, with $\mathrm{M}: \mathrm{F}=2.1: 1$ and $41.5 \%$ from orthopaedics. There were $111(\mathrm{n}=27.8 \%)$ children between 0 and 10 years, $54(13.5 \%)$ adolescents, 23 $41.9 \%(n=164)$ were adults between $20-49$ years and $17.8 \%(n=71)$ were adults of ${ }^{24}$ 50 years plus Table 1.

The prevalence of cancellation of elective surgical procedures was found at $28.8 \%{ }^{26}$ $(n=115)$. The prevalence of cancellation among adults between 20 and 49 years of ${ }^{27}$ age was about $35.4 \%(n=58)$ and $32.4 \%(n=23)$ among adults 50 years and above. ${ }^{28}$ The cancellation prevalence among the patients presenting at the Neurosurgery 29 specialty was found at $46.8 \%(n=29)$ Table 1

Many reasons were reported as contributing to cancellation of elective surgical procedure at Mulago hospital. These included; theatre time run out which was reported in 44 cases $(11.0 \%)$, the anesthetist not being on duty $21(5.5 \%)$ and emer- 
gency cases considered as a priority contributed 9 (2.3\%), among other reasons ${ }^{1}$ Table 2

Hospital-related reasons were responsible for more than $2 / 3$ of the cancellations at Mulago Hospital. Figure 1

At bivariate analysis, the patients' age, surgical specialty and operating theatre

had a p-value of less than 0.2 Table 3. They were therefore selected and considered for multivariate analysis.

At multivariate analysis, age and surgical specialty were significantly associated with the cancellation of elective surgical procedures. The odds ratio (95\% confidence interval) for cancellation among adolescents between 11-19 years of age was 0.94 $(0.39,2.24) \mathrm{p}$-value $=0.893$, adults between $20-49$ years was $1.99(1.01,3.98) \mathrm{p}$ value $=0.048$, and among the adults 50 years and above was $2.16(0.96,4.83)$ $\mathrm{p}$-value $=0.061$. The odds ratio for cancellation of elective surgical procedure on the Neurosurgery specialty was $2.35(1.27,4.36)$ p-value $=0.007$ Table 4

* Statistically significant if $\mathrm{P}<0.05$

\section{Discussion}

There is no consensus on acceptable case cancellation rate when defining efficient operating theatres though less than $5 \%$ is generally recommended [14]. Our prevalence of $28.8 \%$ is similar to findings by Ebirim et al. (2012) [15]. This relatively high cancellation rate in our study can be explained by the fact that we investigated all factors associated with cancellation of elective surgery operations including patientrelated factors like having an abnormal preoperative test to facility-related factors like theatre time run out. However, the ongoing renovations with internal readjustments and relocation of theatre spaces may also explain the high cancellation rates.

Different rates of cancellation have been reported basing on the approach of defining cancellation of elective operations (10\% to 40\%) [16]. Rates of cancellation also vary widely depending on the study design, type of hospital and its level and capacity, type of patients (inpatients or outpatients) and on the surgical sub specialty. [4] [9] [11] [16] [17] [18] [19] [20] [21] [22]

Neurosurgery had the highest cancellation rate $(46.8 \%)$ amongst the surgical sub specialties studied. This was probably because they usually have a long theatre list 
which is further worsened by late start of the first case. The high rate may also be ${ }^{1}$ explained by the fact that Neurosurgery has not been working on their neurotrauma 2 emergencies in emergency department during the period the study was conducted. ${ }^{3}$ These cases would then be added onto the elective list thus given priority over ${ }^{4}$ the elective procedures. Super sub specialties like CTS had the least cancellation ${ }^{5}$ rate at $4.3 \%$. This could be explained by the fact that about two to three cases ${ }^{6}$ are scheduled per individual theatre list. However, sub specialties with lower rates ${ }^{7}$ could have had fewer operating days per week as compared to their counterparts ${ }^{8}$ with higher cancellation rates.

9

Facility-related was the category most commonly accounting for cancellation of 11 elective surgical procedures. The findings concur with studies done in Tanzania 12 and Nigeria [23] [24]. The commonest reason under this category was theatre time 13 run-out due to overrun of previous surgery. In sub specialties where facility-related ${ }_{14}$ factors were a common reason for cancellation, it may be that lists were inten- 15 tionally over-booked with view of increasing the likelihood of all cases being done. 16 Pandit et al. (2007) [10] noted that over-booking a list was responsible for half the 17 cancellations due to waiting list pressures and to avoid any perception that the 18 surgical team was not hard-working.

Strategies like operating room turnover time, on-time start of first case, set-up of anaesthesia equipments and any other auxiliary equipments and on-time collection of supplies can be performed in parallel with increases in operating room efficiency. Theatre time run-out in Mulago hospital is multi-factorial and can be reduced by cooperation of all disciplines. The issue of "overtime" payments may offer some incentive to prevent cancellation but overall hospital costs may be very high if overbooking is common. In addition routine and fair estimation of the duration of a procedure can be helpful in improving operating room usage. Shortage of blood was another reason that contributed to elective procedure cancellation. An earlier study by Kajja et al. (2014) [25] noted that lack of blood was a major cause of delayed scheduling of elective surgery. Our study noted that this shortage was mainly observed in paediatric, urology and orthopedic sub specialties. The shortage was probably exacerbated by financial constraints that were reported by the Uganda Blood Transfusion Services (UBTS), the country' s only source of blood during the

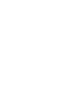


study period. Secondly, it is also possible that some surgical units had not booked blood for their patients prior to the day of the surgery.

There was no procedure canceled in Mulago Hospital for lack of ICU beds during the study period. This finding differs from a 2012 study done in Hong Kong where lack of ICU bed contributed $14 \%$ of the cancellations [26]. This was so because in Mulago ICU bed is requested for prior to scheduling an elective procedure. In case the ICU team confirms non-availability of a bed then the procedure is automatically not put on a particular theatre list for that day. However, it may also be possible that some super specialties are not scheduling highly complex surgeries that require cardiac and respiratory support post-operatively for one reason or another.

Absence of anesthetists was a problem in this study. Similar observations have been found in other studies [19] [23] [27] [28]. Staff shortage and lack of health resources is a common problem in most hospitals in Sub-Saharan Africa [19]. Anesthetist was at times not available because s (he) was attending a workshop or a conference. Considering the resource-limitations, re-distribution of available staffs and appropriate arrangements may be made for internal coverage of annual or study leave. Other reasons like change of diagnosis by the surgeon, with the ultimate change in management plan are preventable. Adequate clinical assessment by all cadres of the surgical team including senior surgeons can mitigate obvious omissions by the junior cadres like surgical residents who are closely involved in drafting the definitive elective surgical list.

Patient-related factors contributed the least to procedure cancellation under the broad category. This was mainly due to abnormal preoperative tests especially low levels of hemoglobin. The situation was compounded by the shortage of blood for perioperative and postoperative blood transfusion. This was different from findings by Gajida et al. (2016) [3] where absconding from surgery and lack of funds to pay for the surgery were the main reasons for cancellation under patient-related factors. This can be explained by the fact that our hospital is a public free- for- service hospital while Amino Kano teaching hospital where Gajida et al. did their study is a federal tertiary hospital but the patients pay a fee-for- service. Other studies in Australia by Haana et al. (2009) [29] and in the UK by Sanjay et al. (2007) [30] also ${ }_{32}^{31}$ differ from our findings, possibly because patients have to pay for surgical services either out-of-pocket or through an insurance scheme. 
The main limitation of this study was that we did not include those patients ${ }^{1}$ who had multiple cancellations. This omission may have somewhat led to underes- 2 timation of cancellation rate considering the fact that some patients are victims of ${ }^{3}$ multiple cancellations.

\section{Conclusions}

The prevalence of cancellation of elective surgical procedures in Mulago Hospital is 7 $28.8 \%$ with Neurosurgery having the highest cancellation rate by sub specialty. Two 8 thirds of the factors responsible for procedure cancellations were facility related with 9 more than fifty percent of them being potentially preventable. Despite the above, 10 quality improvement strategies are necessary in those sub specialties susceptible to 11 procedure cancellations due to facility factors. 12

List of abbreviations 13

CI: Confidence interval; CTS: Cardiothoracic Surgery; ENT: Ear, Nose and 14 Throat; ICU: Intensive Care Unit; UCI: Uganda cancer institute; UK: United King- 15 dom 16

$\begin{array}{ll}\text { Declarations: } & 17\end{array}$

$\begin{array}{lc}\text { Ethics approval and consent to participate } & 18\end{array}$

This study was approved by School of Medicine Research and Ethics Committee of 19 Makerere University College of Health Sciences, registered as \#REC REF 2018- 20 007 and written informed consent was obtained from participants and/ or their 21 next of kin.

$\begin{array}{lr}\text { Consent for publication } & 23\end{array}$

Not applicable $\quad 24$

Availability of data and materials 26

Data for this study are available from the corresponding author upon reasonable 27 $\begin{array}{ll}\text { request. } & 28\end{array}$

\section{Competing interests}

The authors declare that they have no competing interests

\section{Funding}




\section{Authors' contributions}

$\mathrm{AO}^{1}$ : conceived the study, and participated in its design and coordination, data acquisition, statistical analysis and helped to draft the manuscript; $\mathrm{FO}^{1}$ : participated in its design, statistical analysis, interpretation and drafting of manuscript ; $\mathrm{EN}^{1}$ : involved in data acquisition, and interpretation ; $\mathrm{TKM}^{1,2}$ and $\mathrm{FMG}^{1}$ : involved in design, data analysis, interpretation, drafting and review of manuscript.

\section{Acknowledgments}

We acknowledge the theatre staff of MNRTH for helping in the data collection. The authors also thank all members of the surgical department, College of Health Sciences, Makerere University, especially Prof. Stephen C. Kijjambu and MR. Ocen William for their contributions during the proposal stage. We also thank Miss Beinomugisha Christine for her contribution towards data entry and editing. And finally our biostatistician Sam Ali Baker for his enormous contribution to this piece of work.

\section{Author details}

${ }^{1}$ Surgery, Makerere University, College of Health Sciences, Kampala, Uganda. ${ }^{2}$ Surgery, Mulago National Referral and Teaching Hospital.

\section{References}

1. Rai, M.R., Pandit, J.J.: Day of surgery cancellations after nurse-led pre-assessment in an elective surgical centre: the first 2 years. Anaesthesia 58(7), 692-701 (2003)

2. Trentman, q.., TI, q., Mueller, J.T., Fassett, S.L., Dormer, C.L., Weinmeister, K.P.: Day of surgery cancellations in a tertiary care hospital. Journal of Anesthesia and Clinical Research 1(3) (2010)

3. Gajida, A., Takai, I., Nuhu, Y.: Cancellations of elective surgical procedures performed at a Teaching Hospital in North-West Nigeria. Journal of Medicine in the Tropics 18(2), 108-120 (2016)

4. Gonzalez-Arevalo, A., Gomez-Arnau, J.I., Delacruz, F.J., Marzal, J.M., Ramirez, S., Corral, E.M.: Causes for cancellation of elective surgical procedures in a Spanish general hospital. Anaesthesia 64(5), 487-93 (2009)

5. Fayed, A., Elkouny, A., Zoughaibi, N., Wahabi, H.A.: Elective surgery cancelation on day of surgery: An endless dilemma. Saudi journal of anaesthesia 10(1), 68-73 (2016)

6. Dickerson, S.S., Alqaissi, N., Underhill, M., Lally, R.M.: Surviving the wait: defining support while awaiting breast cancer surgery. Journal of advanced nursing 67(7), 1468-79 (2011)

7. Magnusson, H., Fellnder-Tsai, L., Hansson, M.G., Ryd, L.: Cancellations of elective surgery may cause an inferior postoperative course: the invisible handof health-care prioritization? Clinical Ethics 6(1), 27-31 (2011)

8. Miller, q.: Waiting for an operation: parents' perspectives. Canadian journal of surgery Journal canadien de chirurgie 47(3), 179-81 (2004)

9. Ezike, H., Ajuzieogu, V., Amucheazi, A.: (2011)

10. Pandit, J.J., Westbury, S., Pandit, M.: The concept of surgical operating list 'efficiency': a formula to describe the term. Anaesthesia 62(9), 895-903 (2007)

11. Schofield, W.N., Rubin, G.L., Piza, M., Lai, Y.Y., Sindhusake, D., Fearnside, M.R.: Cancellation of operations on the day of intended surgery at a major Australian referral hospital. The Medical journal of Australia 182(12), 612-617 (2005)

12. Ivarsson, B., Larsson, S., Sjberg, T.: Postponed or cancelled heart operations from the patient's perspective. Journal of nursing management 12(1), 28-36 (2004)

13. Griffin, X., Griffin, D., Berry, A., Hunter, D.: Cancellation of elective surgery-any improvement after ten years? The Bulletin of the Royal College of Surgeons of England 88(1), 28-30 (2006)

14. Marcario A. Are your hospital operating rooms efficient. Anesthesiology 105(2), 237-277 (2006)

15. Ebirim, L., Buowari, D., Ezike, H.: Causes of cancellation of elective surgical operations at a University Teaching Hospital. Journal of Medicine and Medical Sciences 3(5), 297-301 (2012) 
16. ., M., Faori, S.N., Khader, I., ., Y.: Reasons for cancellation of elective operations at a major teaching referral hospital in Jordan/Motifs d'annulation des interventions chirurgicales programmes dans un grand centre hospitalier universitaire de recours en Jordanie. Eastern Mediterranean Health Journal 17(8), 651-651 (2011)

17. Leslie, R.J., Beiko, D., Vlymen, J.V., ., D.: Day of surgery cancellation rates in urology: Identification of modifiable factors. Canadian Urological Association Journal 7(5-6), 167-167 (2013)

18. Keller, A., Ashrafi, A., Ali, A. v1; ref status: indexed (2014)

19. Zafar, A., Mufti, T.S., Griffin, S., Ahmed, S., Ansari, J.A.: Cancelled elective general surgical operations in Ayub Teaching Hospital. Journal of Ayub Medical College, Abbottabad : JAMC 19(3), 64-70 (2007)

20. Kumar, R., Gandhi, R.: Reasons for cancellation of operation on the day of intended surgery in a multidisciplinary 500 bedded hospital. Journal of anaesthesiology, clinical pharmacology 28(1), 66-75 (2012)

21. Dimitriadis, P., lyer, S., Evgeniou, E.: The challenge of cancellations on the day of surgery. International Journal of Surgery 11(10), 1126-1156 (2013)

22. Xue, W., Barnett, Y.Z., Fleisher, R., Liu, L., ., R.: Dynamics of elective case cancellation for inpatient and outpatient in an academic center. Journal of anesthesia \& clinical research 4(5), 314-314 (2013)

23. Chalya, P.L., Gilyoma, J.M., Mabula, J.B., Simbila, S., Ngayomela, I.H., Chandika, A.B.: Incidence, causes and 10 pattern of cancellation of elective surgical operations in a university teaching hospital in the Lake Zone. Tanzania. African health sciences 11(3), 438-481 (2011)

24. Ojo, E., Ihezue, C.: An Audit of day Case Cancellations in a Nigerian Tertiary Hospital based day case unit. 12 East and Central African Journal of Surgery 13(2), 150-153 (2008)

25. I, K. Kajja I. Delayed elective surgery in a major teaching hospital in Uganda, 25-25 (2014)

26. Chiu, C.H., Lee, A., Chui, P.T.: (2012)

27. Robb, W.B., O\&apos;sullivan, M.J., Brannigan, A.E., Bouchier-Hayes, D.J.: (2004)

28. Kolawole, I., Bolaji, B.: Reasons for cancellation of elective surgery in Ilorin. Nigerian Journal of Surgical Research 4(1), 28-33 (2002)

29. Haana, V., Sethuraman, K., Stephens, L., Rosen, H., Meara, J.G.: Case cancellations on the day of surgery: an investigation in an Australian paediatric hospital. ANZ journal of surgery 79(9), 636-676 (2009)

30. Sanjay, P., Dodds, A., Miller, E., Arumugam, P., Woodward, A. Journal of health organization and management (2007) 
Figures

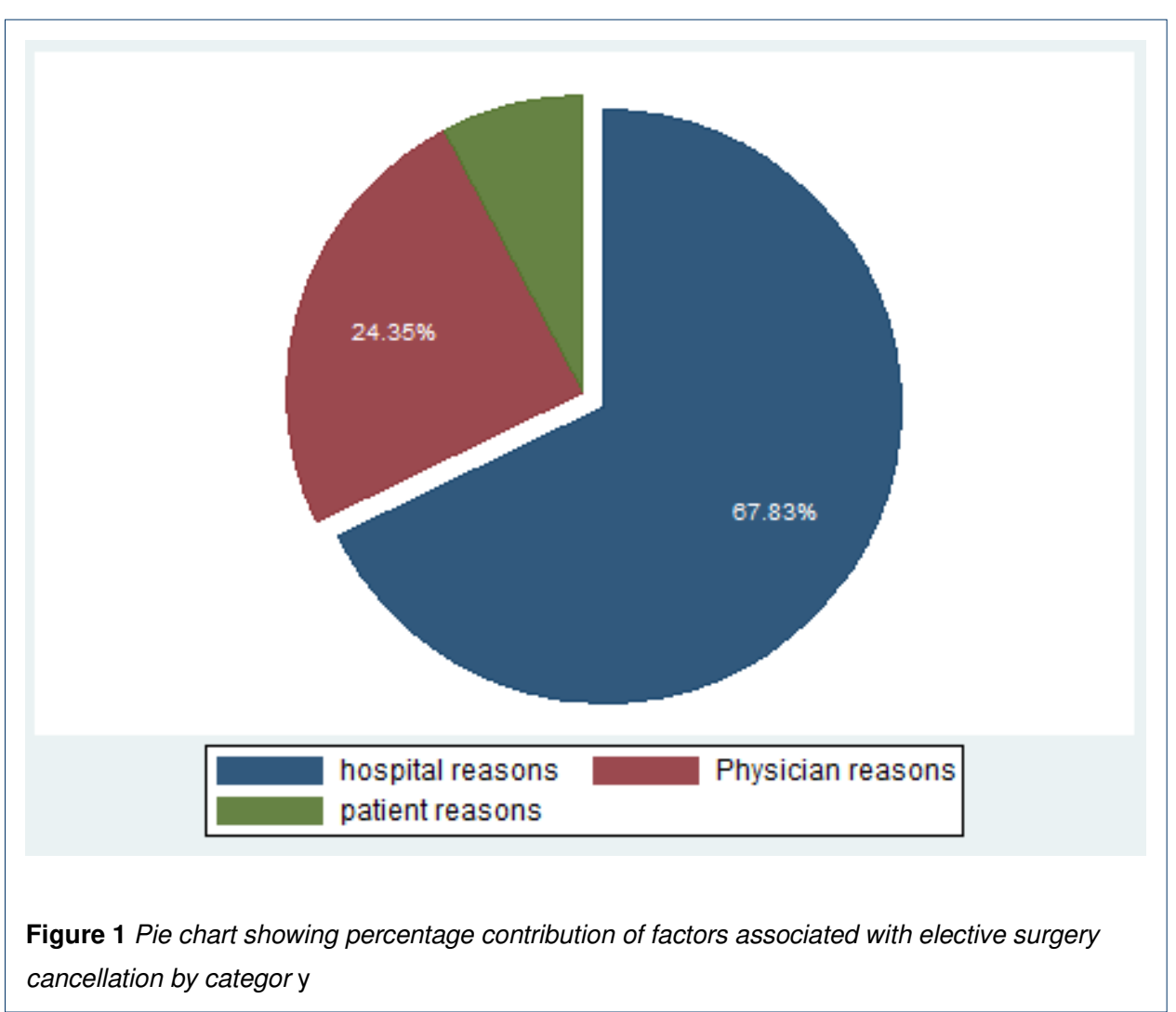

6

7

10

11

12

13

14

15

16

17 


\begin{tabular}{|c|c|c|}
\hline Variable & Frequency, $\mathrm{N}=400(\%)$ & Elective surgery cancelled, n (\%) \\
\hline \multicolumn{3}{|l|}{ Age (years) } \\
\hline $0-9$ & $111(27.8)$ & $22(19.8)$ \\
\hline 10- 19 & $54(13.5)$ & $12(22.2)$ \\
\hline $20-49$ & $164(41.0)$ & $58(35.4)$ \\
\hline $50+$ & $71(17.8)$ & $23(32.4)$ \\
\hline \multicolumn{3}{|l|}{ Gender } \\
\hline Male & $269(67.3)$ & $76(28.3)$ \\
\hline Female & $131(32.7)$ & $39(29.8)$ \\
\hline \multicolumn{3}{|l|}{ Surgical specialty } \\
\hline General surgery & $24(6)$ & $6(25)$ \\
\hline Orthopaedic & $166(41.5)$ & $47(28.3)$ \\
\hline Ear, Nose \& Throat (ENT) & $26(6.5)$ & $3(11.5)$ \\
\hline Urology & $36(9)$ & $15(41.7)$ \\
\hline Neurosurgery & $62(15.5)$ & $29(46.8)$ \\
\hline Cardiothoracic surgery & $23(5.7)$ & $1(4.3)$ \\
\hline Oromaxillofacial (OMF) & $7(1.8)$ & $2(28.6)$ \\
\hline Breast and Endocrine & $18(4.5)$ & $4(22.2)$ \\
\hline Paediatric surgery & $38(9.5)$ & $8(21.1)$ \\
\hline \multicolumn{3}{|l|}{ Theatre } \\
\hline Main operating theatre & $121(30.2)$ & $41(33.9)$ \\
\hline Trauma theatre & $52(13)$ & $12(23.1)$ \\
\hline Ward 7 theatre & $89(22.2)$ & $26(29.2)$ \\
\hline Spine theatre & $43(10.8)$ & $13(30.2)$ \\
\hline Uganda Cancer Institute theatre & $30(7.5)$ & $14(46.7)$ \\
\hline Uganda Heart Institute theatre & $21(5.3)$ & $0(0)$ \\
\hline Naguru Paediatric theatre & $44(11)$ & $9(20.5)$ \\
\hline
\end{tabular}


Table 2 The reasons for cancellation of elective procedures on surgical wards at Mulago Hospital, Ugand a

\begin{tabular}{lll}
\hline Variable & Frequency (N) & Percentage(\%) \\
Physician related reasons & & \\
Surgeon with required expertise not present & 2 & 0.5 \\
Surgeon changed diagnosis & 2 & 0.5 \\
Anesthetist not present & 21 & 5.3 \\
Theatre nurse not present & 6 & 1.5 \\
Surgeon changed management plan & 3 & 0.8 \\
Patient related reasons & & \\
Patient did not follow preoperative instructions & 3 & 0.8 \\
Patient declined to undergo the procedure & 1 & 0.2 \\
Patients had abnormal preoperative tests & 7 & 1.8 \\
Patient with undiagnosed congenital heart disease & 1 & 0.2 \\
Patient ran away & 1 & 0.2 \\
Facility related reasons & & \\
Emergency case considereda priority & 9 & 2.3 \\
No sterile instruments or consumables & 5 & 1.2 \\
Power outage before the procedure & 2 & 0.5 \\
No oxygen in the theatre & 2 & 0.5 \\
Broken or unavailable equipment & 6 & 1.5 \\
Theatre time run out & 44 & 11.0 \\
Impromptu theatre fumigation Shortage of blood & 46 & 1.01 .5 \\
No ambulance to transfer patient to post-operative ward & 2 & 0.5 \\
No ICU beds & 0 & 17 \\
\hline & & 0 \\
\end{tabular}


Table 3 Bivariate analysis of factors associated with cancellation of elective procedures on surgical 1 wards at Mulago Hospital, Ugand a

\begin{tabular}{|c|c|c|c|}
\hline Variable & Odds ratio (OR) & $\begin{array}{l}95 \% \text { Confidence Inter- } \\
\text { val }\end{array}$ & P-value \\
\hline \multicolumn{4}{|l|}{ Age (years) } \\
\hline $0-9$ (reference) & 1.00 & & \\
\hline $10-19$ & 1.16 & $(0.52,2.55)$ & 0.720 \\
\hline $20-49$ & 2.21 & $(1.25,3.90)$ & 0.006 \\
\hline $50+$ & 1.94 & $(0.98,3.83)$ & 0.057 \\
\hline \multicolumn{4}{|l|}{ Gender } \\
\hline Female (reference) & 1.00 & & \\
\hline Male & 1.07 & $(0.68,1.70)$ & 0.753 \\
\hline \multicolumn{4}{|l|}{ Surgical specialty } \\
\hline Orthopaedics (reference) & 1.00 & & \\
\hline General surgery & 0.84 & $(0.32,2.26)$ & 0.735 \\
\hline Ear, Nose \& Throat (ENT) & 0.33 & $(0.09,1.15)$ & 0.082 \\
\hline Urology & 1.81 & $(0.86,3.80)$ & 0.118 \\
\hline Neurosurgery & 2.23 & $(1.22,4.06)$ & 0.009 \\
\hline Cardiothoracic surgery & 0.12 & $(0.02,0.88)$ & 0.037 \\
\hline Oromaxillofacial (OMF) & 1.01 & $(0.19,5.40)$ & 0.988 \\
\hline Breast and Endocrine & 0.72 & $(0.23,2.31)$ & 0.585 \\
\hline Paediatric surgery & 0.68 & $(0.29,1.58)$ & 0.365 \\
\hline \multicolumn{4}{|l|}{ Theatre } \\
\hline Ward 7 theatre (reference) & 1.00 & & \\
\hline I rauma theatre & 0.13 & $(0.33,1.60)$ & 0.429 \\
\hline Main operating theatre & 1.24 & $(0.69,2.24)$ & 0.473 \\
\hline spıne theatre & 1.05 & $(0.4 /, 2.33)$ & 0.904 \\
\hline $\begin{array}{l}\text { Uganda Cancer Institute the- } \\
\text { atre }\end{array}$ & 2.12 & $(0.91,4.96)$ & 0.083 \\
\hline $\begin{array}{l}\text { Uganda Heart Institute the- } \\
\text { atre }\end{array}$ & - & - & - \\
\hline Naguru paediatric theatre & 0.62 & $(0.26,1.48)$ & 0.283 \\
\hline
\end{tabular}


Table 4 Multivariate analysis of factors associated with cancellation of elective procedures on surgical 1 wards at Mulago Hospital, Ugand a

\begin{tabular}{llll}
\hline Variable & Odds ratio (OR) & $\begin{array}{c}95 \% \\
\text { dence Interval }\end{array}$ & $\begin{array}{c}\text { Confi- } \\
\text { P-value }\end{array}$ \\
Age (years) & & & \\
$0-9$ & 1.00 & $(0.39,2.24)$ & 0.893 \\
$10-19$ & 0.94 & $(1.01,3.98)$ & 0.048 \\
$20-49$ & 1.99 & $(0.96,4.83)$ & 0.061 \\
$50+$ & 2.16 & & \\
Surgical specialty & & & 0.423 \\
Orthopedics & 1.00 & $(0.25,1.80)$ & 0.144 \\
General surgery & 0.67 & $(0.11,1.38)$ & 0.101 \\
Ear, Nose \& Throat (ENT) & 0.39 & $(0.88,4.02)$ & $\mathbf{0 . 0 0 7 *}$ \\
Urology & 1.88 & $(\mathbf{1 . 2 7}, \mathbf{4 . 3 6})$ & 0.053 \\
Neurosurgery & $\mathbf{2 . 3 5}$ & $(0.02,1.02)$ & 0.876 \\
Cardiothoracic surgery & 0.13 & $(0.16,4.72)$ & 0.347 \\
Oromaxillofacial (OMF) & 0.87 & $(0.18,1.84)$ & 0.852 \\
Breast and Endocrine & 0.57 & $(0.41,2.97)$ & \\
Paediatric surgery & 1.10 & & \\
\hline
\end{tabular}

